\title{
Investigating Rainstorm Disturbance on Suspended Substance in Coastal Coral Reef Water Based on MODIS Imagery and Field Measurements
}

\author{
Weiqi Chen ${ }^{1}$, Xuelian Meng ${ }^{1}$, Shuisen Chen ${ }^{2}$, Jia Liu ${ }^{2}$ \\ ${ }^{1}$ Department of Geography and Anthropology, Louisiana State University, Baton Rouge, USA \\ ${ }^{2}$ Guangdong Open Laboratory of Geospatial Information Technology and Application, Guangdong Engineering Technology Center for \\ Remote Sensing Big Data Application, Guangdong Key Laboratory of Remote Sensing and GIS Technology Application, Guangzhou \\ Institute of Geography, Guangzhou, China
}

\section{Email address: \\ smeng@1su.edu (Xuelian Meng)}

\section{To cite this article:}

Weiqi Chen, Xuelian Meng, Shuisen Chen, Jia Liu. Investigating Rainstorm Disturbance on Suspended Substance in Coastal Coral Reef Water Based on MODIS Imagery and Field Measurements. Earth Sciences. Vol. 7, No. 2, 2018, pp. 42-52. doi: 10.11648/j.earth.20180702.11

Received: August 6, 2017; Accepted: September 25, 2017; Published: February 3, 2018

\begin{abstract}
From July 11-12, 2009, the tropical storm Soudeler swept the study area with a Level 8 wind and disturbed the suspended substance in this coastal area, which may have caused some fatal impact on the health condition of coral reef in Xuwen coral reef coast located in Leizhou Peninsula of South China. In order to evaluate the impact of extreme weather on coral reef, this study applied and validated a TSS model to map the TSS variation based on red and infrared spectral bands of MODIS data through one before-storm and two after-storm images after applying the atmospheric correction of in-water linear regression analysis. By mapping and comparing the changes of TSS values before- and after- tropical storm, this study found substantial increases of TSS concentrations as a mean value of $47.8 \mathrm{mg} / \mathrm{L}(\sim 3.6$ times of mean TSS value before rainstorm) in the area during the passage of tropical storm compared to those under no-storm condition. Besides, the TSS returned back to even lower values five days after the passage of tropical storm as a mean value of $3.6 \mathrm{mg} / \mathrm{L}$ ( one quarter of mean TSS value $(13.4 \mathrm{mg} / \mathrm{L})$ before rainstorm). The conclusion was made that the TSS concentration in estuary and coastal areas under local rainstorm tends to return to a normal level faster (approximately 2.5 days) than under a hurricane [1] or tropical storm as discovered in this study (approximately 5 days). Compared to the less frequent and non-synoptic in-situ field sampling approach, the synoptic and frequent sampling facilitated by frequent remote sensing imagery of MODIS provides an improved assessment of TSS concentration and two-dimensional distribution patterns and is recommended to be used as a valuable tool for frequently monitoring coral reef water quality in coastal water bodies of China and other areas in the world if applicable.
\end{abstract}

Keywords: MODIS, TSS, Coastal Coral Reef, Tropical Rainstorm, Investigating

\section{Introduction}

\subsection{Coastal Ecosystem Status}

Coastal ecosystem serves as one of the biggest providers of natural resources to human. Although global coastal areas totals to only $10 \%$ of the land areas, the population in coastal areas take up roughly $60 \%$ of the global population $[2,3,4]$. As the population and economy keeps growing, urban development on the coastal and oceanic resources significantly intensified and a huge number of pollutants were disposed into the ocean at the same time $[2,5,6]$. The coastal ecosystem in the global scale has experienced many non-negligible biological or environmental issues including reduced productivity, decreasing species diversity, and eutrophication of water quality [7], etc. In the past fifty years, the dramatic increases of population and excessive exploitation of resources have caused some irreversible damages on these ecosystems $[8,9,10]$. Hence, maintaining the health of coastal ecosystem is one of the major goals for the global coastal environment and ecosystem management. 


\subsection{The Significance of Coral Reef Ecosystem and Its Degradation}

Coral Reef ecosystem, among all coastal environments, is one of the most diverse ecosystems, featured by its unique biodiversity, wild life habitats for coastal recreation and tourism, fishery and seafood industry, and protection of coastlines $[11,12,13,14]$. As one of the four most productive ecosystems in the world, Coral Reef Ecosystem contains a rich pool of algae types and provides a good habitat environment and food sources for marine species $[15,16,17]$. Thus, the protection of such an ecosystem is critical to preserving the biodiversity in the coastal region and maintaining the sustainable development of coastal fishery $[12,18]$. However, coral reef is a very delicate ecosystem, manifested by its acute response to sea surface, sea temperature, salinity, illumination, seawater clarity, oxygen content, $\mathrm{pH}$ value of seawater and pollution substances [19, 11, 20, 16, 21]. For example, the Xuwen Coral Reef National Reserve in China has degraded from healthy to sub-healthy condition, where the reefs in several coastal areas are experiencing degradation and albefaction, which have severely endangered the entire ecosystem [22]. Monitoring water environments and evaluating the health condition of coral reef areas is thus significant for coral reef preservation.

Water parameters such as chlorophyll-a, total suspended substance (TSS), turbidity, salinity, and temperature are useful health indicators of hydrological ecosystems. TSS is one of the most important parameters that affect this coral reef area in the study, along with the other two: petroleum and phytoplankton productivity. Excessive sedimentation can adversely affect the structure and function of the coral reef ecosystem because heavy sedimentation is often associated with fewer coral species, less live coral, lower coral growth rates, greater abundance of branching forms, reduced coral recruitment, decreased net productivity of corals, and slower reef accretion rates [23]. In contrast, the coral reef in water bodies with less sediments grow better with more types of corals, a higher coverage of corals, and a faster growing rate. For example, in Santa Cruz, United States, the west area with a lower sedimentation rate has a higher coverage of live corals and more diversified species when compared with the east area of a high sedimentation rate [24]; while in other areas where the sedimentation rate are close to each other, their coverage of corals and variety of species are also similar [25].

Due to the complicated influencing factors, the coral reefs in our study area have presented a sign of degradation during the period of $2000 \sim 2004$, where the coverage rate of coral on the fore-reef slope decreased from $30 \% \sim 40 \%$ to $10 \%$ [26]. Also, previous reports indicate that the coral reef degradation caused by rainstorm can cause mass mortality of fishes in the affected areas, thus affecting the ecosystem of the area as a whole $[15,27]$. In 2006, the status of coral reef ecological system in southwest coast of Leizhou Peninsula was degraded from healthy to sub-healthy and lingered between healthy and sub-healthy condition since 2006 [28].

As an important environmental parameter of water quality, a high level of TSS indicate a severely degraded coral reef ecosystem health, which may cause death of coral and related creatures when exposed to long duration of high TSS after extreme events. Recently, using remote sensing techniques to estimate TSS has become an important method to monitor water quality in different types of water bodies [29, 30, 31, 32]. Besides TSS, other commonly used water quality indices include water clarity, turbidity, etc. The turbidity is a type of effect that is related to the concentration of TSS and other impurity elements in water and is observable from remotely sensed imagery [1]. It was found that variations in turbidity help understand the distribution of TSS and procedures like coastal erosions and mobilization of chemicals or pollutants [33]. Udy et al. (2005) [34] found a strong correlation between turbidity and TSS with a determination coefficient $\left(R^{2}\right)$ of 0.88 in the central Great Barrier Reef Lagoon, Australia. Chen et al. (2009) [1] had a similar finding in his case study conducted in China, which also proved the correlation between the two.

In a case study in New York Harbor regions, Hellweger et al. (2004) [35] found that the turbidity, determined from the Secchi depth, is correlated with the $30 \mathrm{~m}$ resolution Landsat TM red band reflectance (630-690nm). Li (2010) [36] used the concentration of suspended substance retrieved from Moderate Resolution Imaging Spectroradiometer (MERIS) images as the input of physical model and produced an ecological model for short-term prediction of Southern North Sea algal dynamics. Jiang et al (2011) [37] adopted algorithms with three types of inputs, including single band, spectra ratio of two bands and reflectance first-derivative, to estimate TSS in Qingshan Lake in China and found that the first-derivative input resulted in most estimation accuracy.

Natural disturbances such as rainstorms, El Nino weather effects, and human activities often cause huge damages to coral reefs according to previous research $[38,39,40,41]$, indicating that special events could likely bring dramatic changes to coral reef water. Our study area, as the only coral reef reserve along mainland China, has experienced significant water quality degradation according to national reports [42]. No related reports were found in this specific area on the estimation of water quality using TSS as an indicator. Considering the significance of this area, especially its effect on the surrounding ecosystem health, this study intends to apply the remote sensing model in the area and explore its applicability herein.

Based on the above reasons, this study investigates the TSS spatial-temporal changes in this area. The goal is to investigate the effects of rainstorm events on coastal coral reef water by studying the dynamic distribution of TSS based on the study site in southwest coast of Leizhou Peninsula of South China. A TSS model is validated in Apalachicola Bay, FL [28] and applied to map the TSS concentration in this study based on before- and after-rainstorm moderateresolution imaging spectroradiometer (MODIS) images. The results of TSS changes are analyzed along with the spatial distribution patterns in core coral reef areas. 


\section{Study Area \& Data}

\subsection{Study Area}

Xuwen County of Guangdong Province, South China is the only coral reef nature reserve near the mainland of China, which was formed roughly ten thousand years ago. It is located in Beibu Gulf, the coastal area to the southwest of Leizhou Peninsula. To the east and south of Beibu Gulf are Leizhou Peninsula and Hainan Province of China, respectively. The coral reefs in this area spread over $45 \mathrm{~km}$ along the west coast of Jiaowei and Xilian Towns with a total protection area of 14378.5 ha (Figure 1), including a core area of 4356.1 ha, a buffer area of 4665.2 ha, and an experiment area of 5357.2 ha as outlined by the government. The division of different areas is based on its natural environment, status of resources, and the urgency for protection. As mentioned above, coral reef in the area has undergone a severe degradation of water quality, reported by the National Bureau of Oceanography of China.

The rainstorm approximately started on July 11, 2009 at 2:00 pm and stopped on July 12 at 8:00 pm, which was caused by a tropical storm named Soudelor. Soudelor was Serial No. 5 of tropical storms of China in 2009 with a maximum wind speed of $18 \mathrm{~m} / \mathrm{s}$, reaching a Level 8 of wind power. It was formed on July 11 and later on that day the storm crossed Leizhou Peninsula. Soudelor mainly brings rainstorms to the west and south of the storm center covering several coastal regions of Hainan and Guangdong Province. Since it brings strong rainstorms in our areas of interest, it provides a good case for studying the effect of rainstorm on coral reef water in our study area. The study area shown in Figure 1 is displayed using MODIS data.
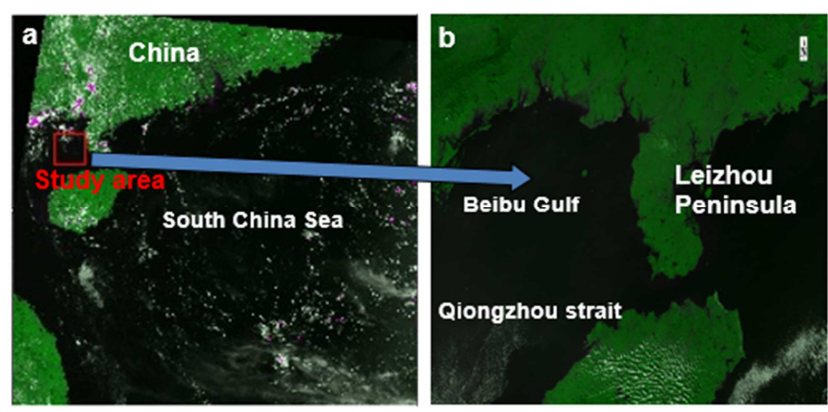

Figure 1. Location of the Study Area Illustrated in 250-m resolution MODIS Imagery (Image Composition: $R G B$ Band 1, 2, 1). a) Overview Image of South China Sea. b) Zoomed-in Image of the Study Area.

\subsection{Data}

MODIS data have gained more attention in the application of TSS estimation in water bodies than Landsat TM data because of the improved spectral resolution (36 bands) with bands sensitive to water, higher temporal resolution (twice a day instead of 16 days interval of Landsat TM data) to capture highly dynamic water status before and after a storm, and a higher radiometric resolution sensitive to small changes of values. Previous studies of different water bodies such as small bay areas, lakes, and estuarine areas have reported strong correlations between water quality parameters and band 1 (620-670 $\mathrm{nm}$ in red) and band 2 (841-876 $\mathrm{nm}$ in near infrared or NIR) of MODIS imagery [1, 43, 44]. Therefore, this study selected band 1 and 2 for TSS estimation.

The MODIS images can be downloaded from the NASA website http://modis.gsfc.nasa.gov/. The lat/long of the study area is approx. $20.2^{\circ}-20.5^{\circ} \mathrm{N}, 109.8^{\circ}-110.0^{\circ} \mathrm{E}$, and the WRS-2 path and row for Landsat are 124 and 46 respectively. Three MODIS images, including some day before the rainstorm event, second day after the rainstorm event, and fifth day after rainstorm (local time 10:45 a.m. on July 9, 2009; 1:30 p.m. on July 14, 2009; 11:35 a.m. on July 17, 2009 respectively), were used to study the TSS changes. Another MODIS image on December 3, 2010 (local time 1:50 p.m.) with concurrent in-situ TSS data was used to validate the TSS model. A total of 18 in-situ TSS sample points were collected on December 3, 2010 by cruising in field and analyzed in laboratory according to corresponding specification (GB 11901-89, 1990). The study used the MODIS image in 2010 and the in-situ TSS measurements for model validation. Final results of TSS were retrieved and mapped using the model and the MODIS images in 2009 pre- and post-rainstorm. TSS values were measured and recorded as the water quality parameter. The field spectra and water parameter measurements provide a basis for development and validation (validation in our case) of the model between spectral reflectance and TSS.

\section{Methodology}

\subsection{Preprocessing of Remote Sensing}

\subsubsection{Projection Transformation and Spatial Subset}

All the images, including the three images in 2009 and the image in 2010 for validation, are corrected to the UTM projection in zone $49 \mathrm{~N}$. The datum used for projection is WGS-84. To conduct the spatial subset, the area desired was selected and exported with the specific latitude/longitude using the tool Region of Interest in ENVI 4.5.

\subsubsection{Separation of Water and Land}

In order to estimate TSS in water bodies, the spectral subset was conducted to separate water and land based on their different reflectance. By examining the spectral profile across water and land objects in near infrared band, the reflectance of water bodies is usually lower than those from the land due to the strong absorption of near infrared light in water. Based on the reflectance characteristics of these objects, a threshold value was identified and applied to remove land area. The threshold value can be determined through spectral profile by drawing a line across water bodies and land and it may vary from image to image. For example, for images of July 9, 2009 and December 3, 2010, the threshold values are set to 0.025 and 0.06 respectively after examining the spectral profiles in water and across both water and land as illustrated in Figure 2. 

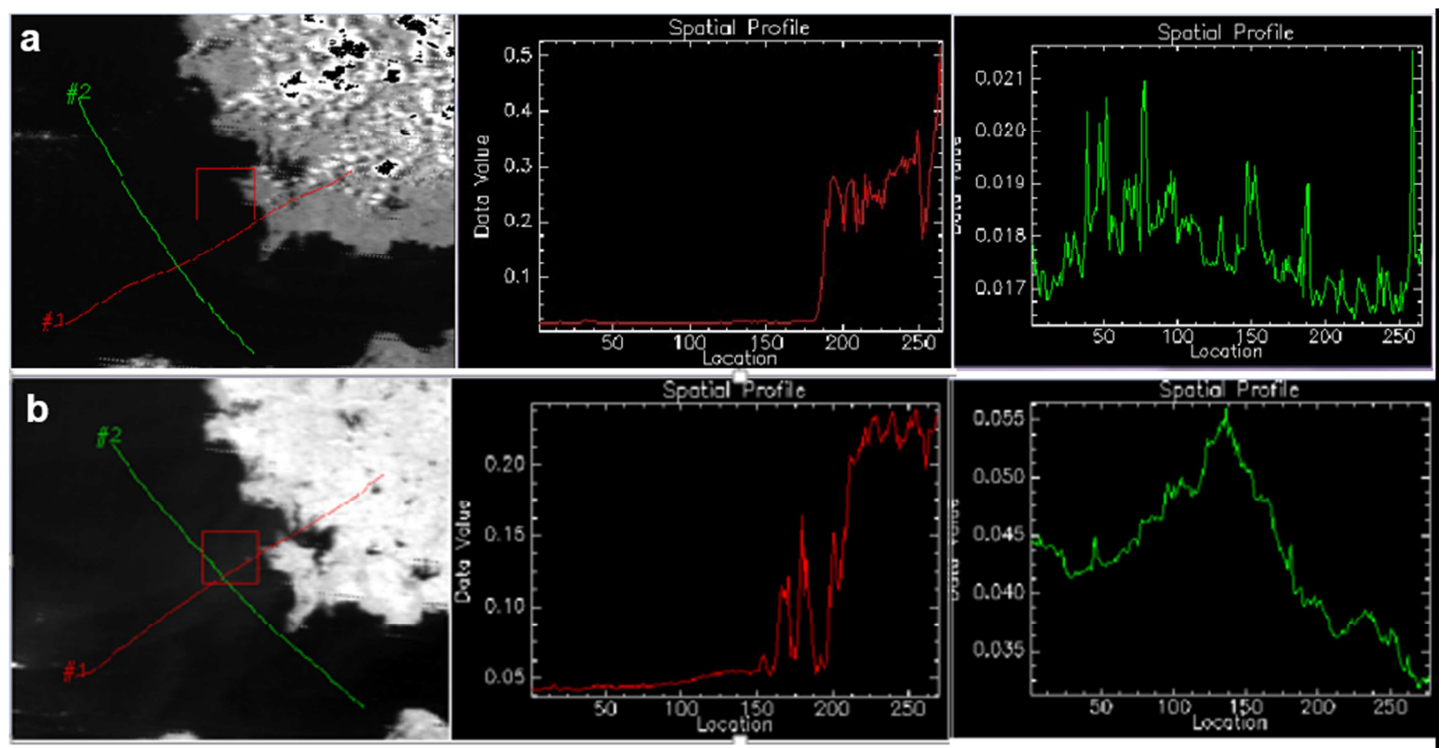

Figure 2. a) Spectral Profiles of the Two Randomly Drawn Lines on Water and Land, NIR Band, Image on July 9, 2009. b) Spectral Profiles of the Two Randomly Drawn Lines on Water and Land, NIR Band, Image on December 3, 2010. Red Line is Across Water and Land, and Green Line is within water.

\subsubsection{Atmospheric Correction: In-water Linear Regression Analysis}

Atmospheric correction aims to retrieve surface reflectance from remotely sensed imagery under clear sky condition by removing noise from atmospheric effects which prevent proper interpretation of images [45, 46, 47]. Such process is often necessary for quantitative assessment of environmental parameters such as TSS due to their sensitivity to noises in the involved bands. Chen et al. (2010) [28] compared two atmospheric correction methods to study the impact of a rainstorm event on the rainstorm-induced sediment plume area in Apalachicola Bay, FL. By comparing the traditional method of Dark Object Subtraction (DOS) and in-water linear regression analysis, his results reported higher accuracy from the in-water MODIS regression analysis based on band 1 and band 2 than from the DOS method [48, 1]. The regression analysis based on the correlation between the red and NIR bands was used for atmospheric correction to remove noise from both bands.

This particular method is applied and verified for atmospheric correction in this study. The regression formula was built by taking the pixel values of all objects in red and NIR bands as the longitudinal (y axis) and horizontal ( $\mathrm{x}$ axis) coordinates respectively. The y intercept is considered as the atmospheric noise in the scene and used as the pixel value being subtracted from the two bands. Because of the proved higher accuracy of the in-water regression method in the water area, this method was conducted to obtain the intercept of linear equations for all the three images used in 2009 (two images) and 2010 (one image) in this study as demonstrated in Figure 3 [28]. The MODIS b1/b2 regression analysis produced a high $\mathrm{R}^{2}$ (above 0.85 ) for all three images, proving the effectiveness of the regression analysis. For example, the noise values due to atmospheric effects are 0.007 and 0.001 for the two MODIS images before and after the rainstorm, on date July 9 and July 14 respectively. These two values are extracted from the equation below as in Figure $3 \mathrm{a}$ and $3 \mathrm{~b}$.

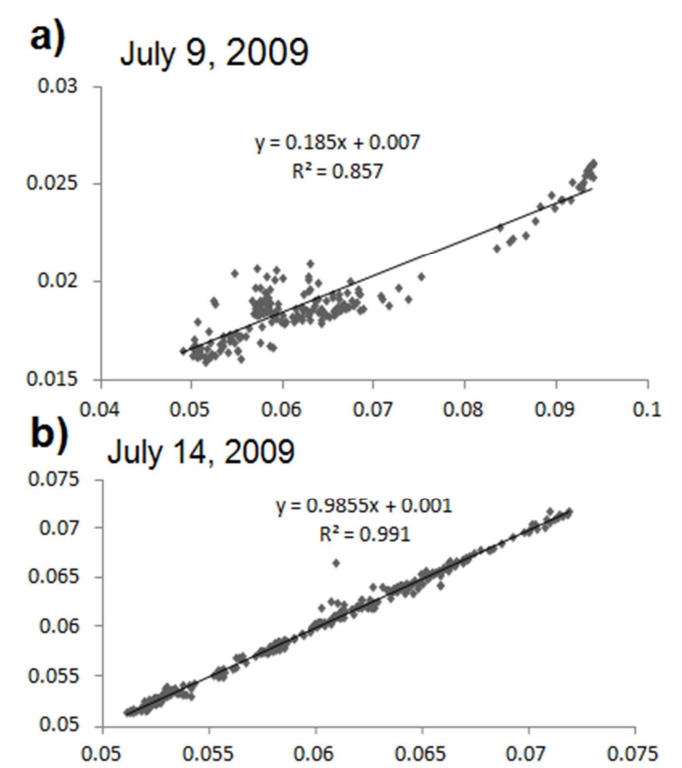

c) December 3, 2010

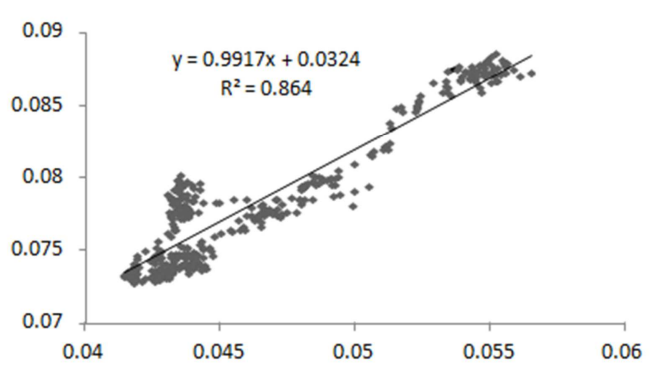

Figure 3. Regression Analysis Based on Red and NIR Bands of the Images Acquired on a) July 9, 2009, b) July 14, 2009, c) December 3, 2010 (for Validation). Red Band and NIR Band are Used as the Horizontal (x axis) and Longitudinal (y Axis) Coordinates Respectively. The intercept is the Pixel Values to be Subtracted from the Respective Bands and Used for Atmospheric Correction. 


\subsection{TSS Model}

In the case study of Apalachicola Bay [28], red and NIR bands from Terra/Aqua 250m MODIS level 1 data were used to investigate rainstorm-induced sediment plume characteristics in Apalachicola Bay using an improved TSS model. The model is used to examine the effects of rainstorm on sediment concentration in the bay by comparing MODIS mapping results of TSS concentrations before and after the rainstorm. It was found that the logarithm ratio of MODIS $\mathrm{B} 1 / \mathrm{B} 2$ reflectance have a high correlation with TSS values and could be used to build the TSS inverse model. This TSS model proved a higher accuracy in TSS estimation when compared with other previous TSS estimation method and therefore is used in this study as shown below in Equation 1:

$$
\log (\mathrm{b} 2) / \log (\mathrm{b} 1)=0.4339 * \log (\mathrm{TSS})+0.8288
$$

where TSS is in mg/l and b1 (red) and b2 (NIR) are the reflectance values derived from Terra/Aqua MODIS $250 \mathrm{~m}$ images.

To validate the model for this study area, another MODIS image of December 3, 2010 was acquired. After preprocessing of projection transformation and atmospheric correction (using in-water MODIS b1/b2 regression analysis), TSS values are calculated from the values of b1 and b2 using equation (1). By comparing the TSS results inferred from the model with in-situ TSS data, the mean absolute percentage error (MAPE), the most commonly used measure of forecast error, was used to validate the model. The results indicate that MAPE mostly fall below $20 \%$ with acceptable accuracy [49, 50], making the TSS model applicable in this area.

\section{Result \& Discussion}

\subsection{Mapping Results of TSS Values}

One classified density map was created for each image for the purpose of comparing TSS concentration before and after rainstorm, as shown in Figure 4. The results have revealed substantial TSS increases at a mean value of $47.8 \mathrm{mg} / \mathrm{L}(\sim 3.6$ times of mean TSS value before rainstorm) in the second image of July 14, 2009, two days after the rainstorm. Table 1 lists the brief statistical summary of the TSS values for the three images. In this table, a percentile is a measure used in statistics indicating the value below which a given percentage of observations in a group of observations fall. For example, the 20th percentile is the value below which 20 percent of the observations may be found. a) July 9

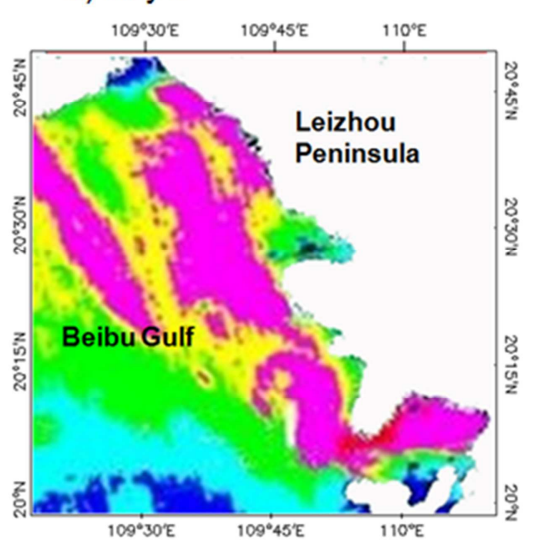

b) July 14

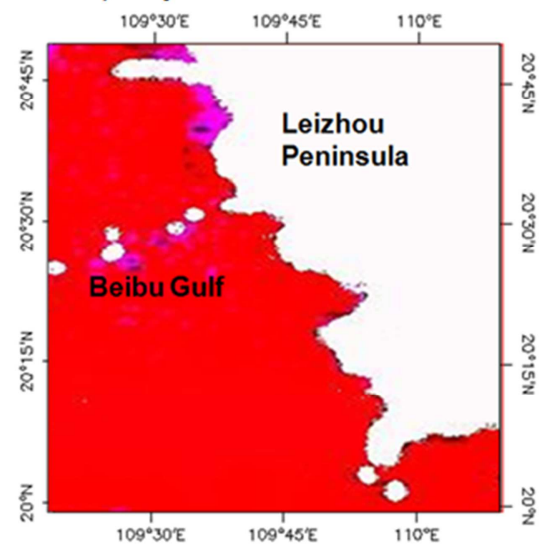

c) July 17

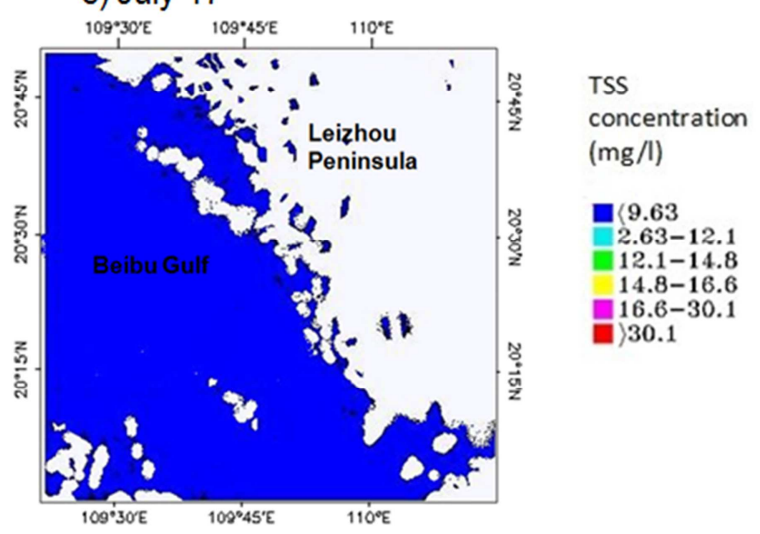

Figure 4. Classified Density Maps of TSS Concentrations Derived from MODIS Mapping Before and After the Rainstorm Event of July 11-12, 2009. a) 10:45 a.m. on July 9, 2009 (Two Days Before the Rainstorm). b) 1:30 p.m. on July 14, 2009 (Two Days After the Rainstorm). c) 11:35 a.m. on July 17, 2009 (Five Days After the Rainstorm). 
Table 1. Statistics of MODIS Deduced TSS Values (mg/l) Before and After Rainstorm.

\begin{tabular}{llll}
\hline & Jul.9,2009 & Jul.14,2009 & Jul.17, 2009 \\
\hline Maximum & 37.2 & 123 & 8.3 \\
Minimum & 2.6 & 11.4 & 0.3 \\
Mean & 13.4 & 47.8 & 3.6 \\
Stdev & 4.1 & 16.6 & 0.7 \\
20th percentile & 9.5 & 35 & 3.2 \\
40th percentile & 9.5 & 42 & 3.5 \\
60th percentile & 9.5 & 47.5 & 3.7 \\
80th percentile & 9.5 & 55.5 & 4 \\
90th percentile & 9.5 & 68 & 4.2 \\
99th percentile & 9.5 & 105.9 & 6 \\
\hline
\end{tabular}

\subsection{Discussion}

By comparing the TSS values before and after the rainstorm, the results indicated that the rainstorm caused an overall increase of TSS values in the area with most regions experiencing a triple increase. Before the rainstorm, the TSS had a tendency of increasing from the middle Qiongzhou Strait to the coast (from west to east in Figure 1), which was common in most coastal waters. From the farther part of the gulf to the coastal area, TSS values increased from below $9.63 \mathrm{mg} / \mathrm{L}$ to between $18-30 \mathrm{mg} / \mathrm{L}$ in most areas as illustrated in Figure 4a.

Two days (71 hours) after the rainstorm (Figure 4), the average TSS concentrations increased dramatically from 13.5 $\mathrm{mg} / \mathrm{L}$ to $47.8 \mathrm{mg} / \mathrm{L}$ and the maximum TSS increased from $37.2 \mathrm{mg} / \mathrm{L}$ to $123 \mathrm{mg} / \mathrm{L}$. After five days (141 hours in total), TSS values dropped to even lower values (the average and maximum TSS about $3.6 \mathrm{mg} / \mathrm{L}$ and $8.3 \mathrm{mg} / \mathrm{L}$ ) than before the rainstorm as indicated in Figure 4c. Also a significant increase of standard deviation of TSS values could be detected in the date of July $14(16.6 \mathrm{mg} / \mathrm{L})$ when compared with that of date July $9(4.1 \mathrm{mg} / \mathrm{L})$, indicating that the variance of TSS values is much higher as TSS values increases itself. The standard deviation of July 17 was the lowest of all $(0.7 \mathrm{mg} / \mathrm{L})$, indicating that July 17 sees the lowest variance of TSS values in the study area. Although, on July 14 when TSS was the highest of all, 90\% of areas had the TSS values lower than $68 \mathrm{mg} / \mathrm{L}$ and over $98 \%$ area had TSS values below $100 \mathrm{mg} / \mathrm{l}$, with only few pixels reaching above the value of $100 \mathrm{mg} / \mathrm{L}$.

A thorough analysis of Figure $4 \mathrm{a}, 4 \mathrm{~b}$ and $4 \mathrm{c}$ for the images of date July 9, 14, and 17, 2009 respectively give detailed information of the spatial and temporal TSS variance in this area within the specific period of time. Figure $4 \mathrm{a}$ indicates the TSS values before the rainstorm (July 9, 2009) had a tendency of increasing in banded shape from the middle strait to the coast of Leizhou Peninsula with an average TSS value of about $13.5 \mathrm{mg} / \mathrm{L}$. The ring shape of TSS distribution in this period was probably due to the integrated influence of ocean currents and terrain, especially human activity. Figure $4 \mathrm{~b}$ shows significant increase of TSS values in the whole study area as of July 14, 2009, with the highest TSS values among all (average TSS about $47.8 \mathrm{mg} / \mathrm{L}$ ). The rainstorm brought by the tropical storm Soudelor is the immediate reason that caused this dramatic change of TSS values. It can be imaged that the TSS values reached higher values during the rainstorm passing [28] although no cloud-free images were acquired. Figure 4c saw the lowest TSS values among the three images (average TSS about $3.6 \mathrm{mg} / \mathrm{L}$ ), which could attribute to the relatively low frequency and intensity of human activities immediately (two days) after the rainstorm. In addition, other factors such as wind directions and tide changes can impact the TSS changes as well [51].

Another map in Figure 5 revealed TSS changes by displaying TSS values that fall in each category. It is evident that in the image of July 9, the TSS values in coastal areas mostly fall in category of $10-20 \mathrm{mg} / \mathrm{l}$, while the farther strait area falls in category of $0-10 \mathrm{mg} / \mathrm{l}$. For the image of July 14, the TSS values in coastal areas have dramatic increased and fall in the level of 30-50, 50-100, or even 100-123 mg/l in the eastern coastal areas. This confirms that TSS values have a nearly triple increase in the study region, especially the coastal areas. By contrast, for the image of July 17, the TSS values drop down to the category of below $10 \mathrm{mg} / \mathrm{l}$. Also, the TSS spatial distribution from Figure $5 \mathrm{~b}$ shows a higher TSS concentration in the east and south areas and relatively lower concentration in the northern areas, indicating an eastward sediment transport caused by the storm. This approach effectively illustrates the detailed distribution of TSS values, and how they differ spatially - from the coastal to farther strait areas, and temporally - from before the rainstorm, to immediately after the rainstorm, and to five days after the rainstorm.

The statistical results of this density map indicate that for the image of July 9, 2009 (Figure 5a), the areas have TSS values between $0-10,10-20,20-30$, with those above 30 $\mathrm{mg} / \mathrm{L}$ taking up $24 \%, 72.5 \%, 2.8 \%$, and $0.7 \%$ of the entire area respectively. While for the image of July 14 (Figure 5b), the areas have TSS values between 10-20, 20-30, 30-50, 50100 , and $100-123 \mathrm{mg} / \mathrm{L}$ with a percentage of $0.75 \%, 9.75 \%$, $58.8 \%, 29 \%, 1.7 \%$ respectively. No areas fall in category of below $10 \mathrm{mg} / \mathrm{L}$ in this image. For the image of July 17 (Figure 5c), all the areas have TSS values below $10 \mathrm{mg} / \mathrm{L}$ with approximately half to be even lower than $3.6 \mathrm{mg} / \mathrm{L}$. The area percentages with different TSS values not only indicate the TSS changes of the three images in percentage groups but also show the overall TSS distribution changes of the three different times. 
a) July 9

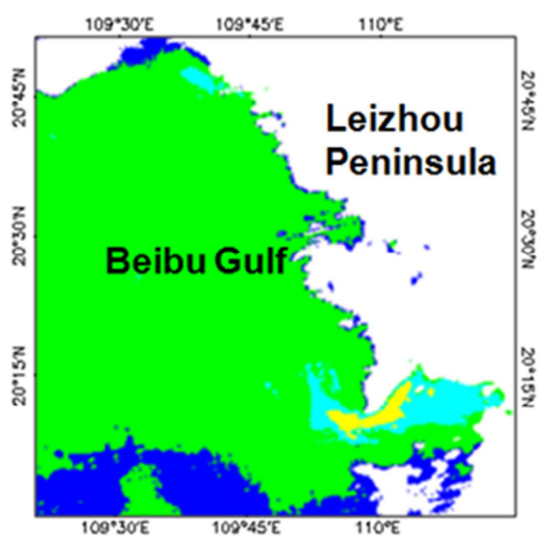

b) July 14

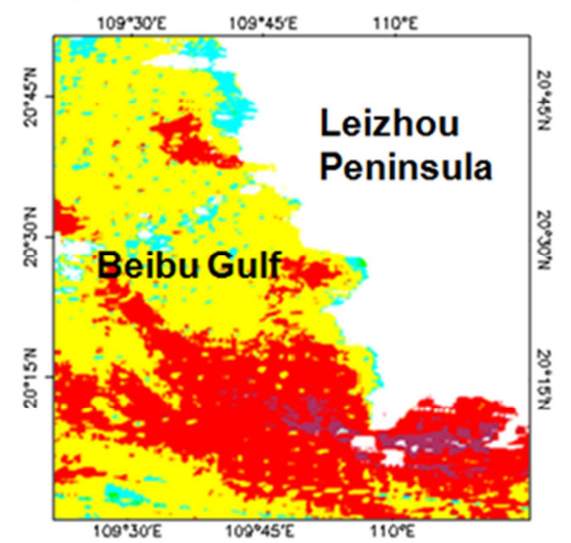

c) July 17

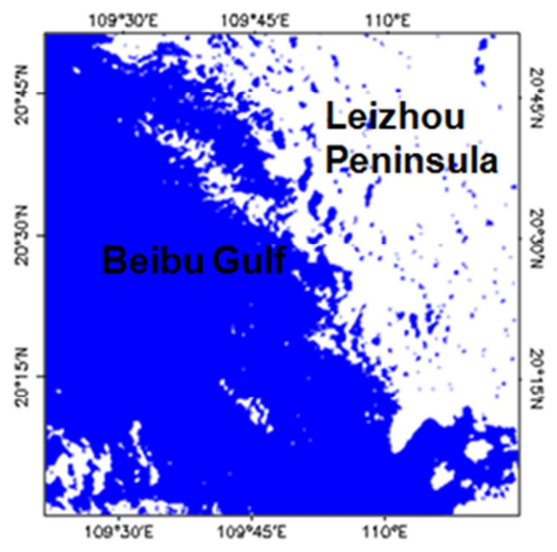

TSS

concentration (mg/l)

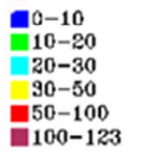

Figure 5. Classified Density Maps of TSS Categories. a) 10:45 a.m. on July 9, 2009 (Before the Rainstorm). b) 1:30 p.m. on July 14, 2009 (two days after the rainstorm). c) 11:35 a.m. on July 17, 2009 (Five Days After the Rainstorm).

a) July 14 overlap with TSS> $50 \mathrm{mg} / \mathrm{l}$

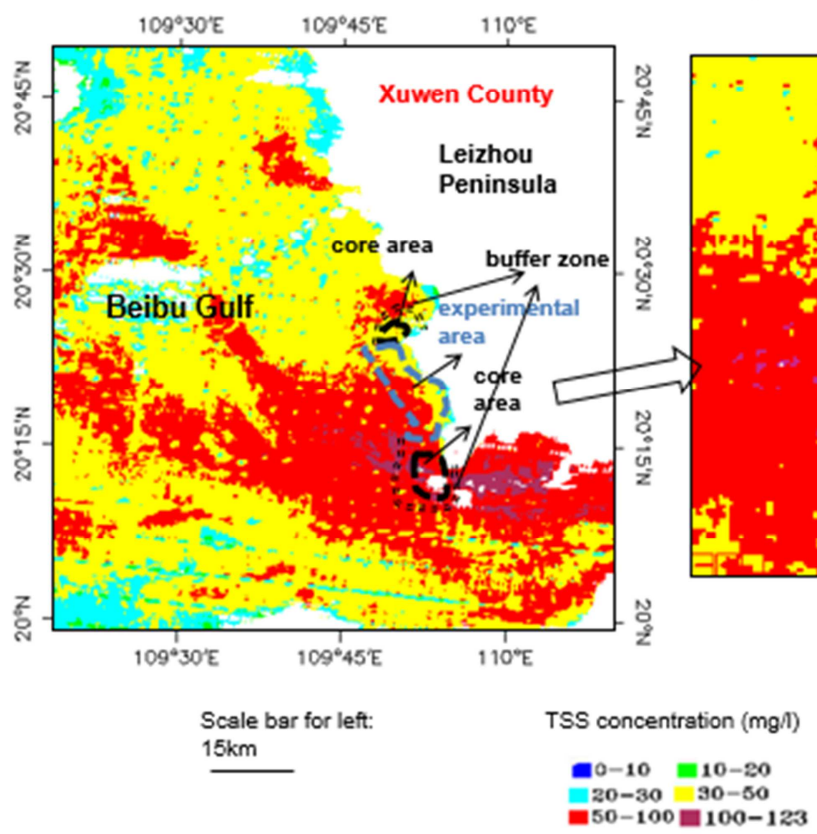

b) Zoom in 
Figure 6 displays the image of July 14 (same to Figure $5 \mathrm{~b}$ ) together with the distribution of coral reef core and experimental areas in the region along Xuwen County coast. By comparing the TSS values on July 14 and the main coral reef reserve areas, it is evident that the experimental and core coral reef areas overlap with the areas that have the most significant TSS increase, falling within the high TSS categories such as 30-50, 50-100, and 100-123 mg/l. According to statistical results, the experimental coral reef area has a percent of $4.2 \%$ that overlaps with the TSS values higher than $50 \mathrm{mg} / \mathrm{l}$ (represented by red and maroon in the map). The core coral reef area in the south (see Figure 6) has a percent of $74.9 \%$ that overlaps with TSS higher than 50 $\mathrm{mg} / \mathrm{l}$, indicating a larger impacted area by higher TSS concentrations during the rainstorm. The overall overlapping percent of the coral reef reserve areas with TSS values that are higher than $50 \mathrm{mg} / \mathrm{L}$ reaches $32.9 \%$.

A significant finding of this study is that after five days of the rainstorm, TSS values fell to a lower value than before the rainstorm in the study area. On July 17 the study area sees a lower average TSS value (3.6 compared with 13.5 of July 9) indicating an overall decrease of TSS values, and a lower standard deviation ( 0.7 compared with 4.1 of July 9 ) indicating a smaller variance in the whole area. Previous studies also had similar findings on this particular issue. Chen et al. (2009) did a study on the impact of Hurricane Frances on TSS concentration in Apalachicola Bay area in the United States and found that the TSS concentration gets back to normal after five days of the hurricane. Hurricane Frances was a Category 4 Hurricane, with gusts from 40 miles per hour $(64 \mathrm{~km} / \mathrm{h})$ to as high as 87 miles per hour $(140$ $\mathrm{km} / \mathrm{h}$ ), and maximum sustained wind speed being $145 \mathrm{mph}$ $(230 \mathrm{~km} / \mathrm{h})$. Another study of the same area on TSS concentration changes [28] found that the surface TSS concentrations can get back to their reference values after 60 $\mathrm{h}$ and $50 \mathrm{~min}$ (i.e. almost the day 2.5) of the rainstorm. Hence, it can be seen that the impact and duration of storms (i.e. how long it takes TSS values to go back to normal values) on TSS varies from place to place depends on many local factors, such as the bay size and shape, river runoff, human activities, and most importantly the level of wind force. Generally, the TSS concentration in estuary and coastal areas under local rainstorm tends to return to normal level (2.5 days) faster than under tropical storm or hurricane (5 days).

The finding that TSS in 5 days after rainstorm (July 17) is even lower than before rainstorm may be due to the reduced intensity and frequency of human activities and hence a lower amount of suspended sediments after a major storm, which indicates that human activities is one of the reasons that keep up the TSS values in the area. That explains why, in general, the values of TSS concentration in the area were the highest immediately after the storm and the lowest few days after tropical storm moving out the area.

Since the long duration of TSS suspension will cause the death of coral reef, high TSS concentration poses an evident and dramatic negative effect on the reservation of coral reef areas (especially at A area). Furthermore, increases of TSS could even bring negative impact to the local economy and human activities. Since the increase of TSS would cause the degradation of water quality and increase the accumulation of TSS sediment on coral surface in coral reef areas, the deterioration of the ecological system could then cause the decline of fish group quantity and quality. Dahl A L. (1985) [15] and Rogers C S. (1982) [27] found that in Caribbean Sea and Pacific areas, the degradation of coral reef and mangroves caused by TSS and sedimentation was one reason that causes the decline of the tropical fishery in the area.

\section{Conclusion}

The results of the study show that averaged TSS concentrations have experienced a nearly triple fold increase in the study area due to the passage of tropical storm Soudelor with a Level 8 wind power when compared to under no-storm condition. Two days after the rainstorm (a total of 71.5 hours) beyond the time of first image, TSS values tripled in most areas, and this change is more obvious in coastal areas than in the strait areas. The TSS dropped to even lower values than before the rainstorm in five days after the tropical storm moved out of the region.

By comparing with the case study on TSS values in storm period ${ }^{[28]}$ with the current study, it indicates that the TSS concentration in estuary and near-coast ocean under local rainstorm tends to return to normal level faster (approximately 2-3 days) than under a hurricane ${ }^{[1]}$ or tropical storm as in this study (approximately 5 days). The MODIS mapping analysis of TSS indicated that the tropical rainstorms exert significant increases on the TSS levels (higher average values of TSS) and variations of spatial distribution (higher variance) across the study area. After tropical rainstorm, it is nearly a triple increase of TSS in most areas, and the coastal region has seen the most significant TSS increase among all. After tropical rainstorm on July 14, 2009, the statistics in core and experimental coral reef areas (Figure 5) indicates an overall $32.9 \%$ overlapping between the areas of high TSS concentration $(>50 \mathrm{mg} / \mathrm{L})$ and all coral reef areas (including experimental, and two core areas: Jiaowei and Xilian) along the south-west coastal region of Leizhou Peninsula (marked by circles in Figure 6).

Since the suspension of TSS could jeopardize the ecological health of the coral reef reserves area [23, 24], climatic events such as tropical storms likely have a negative impact on the coral reef reserves, and policies and warning activities should be arranged to provide a better protection for these areas considering their biodiversity and ecological significance. Furthermore, there is a need to further study the specific effect of TSS change (such as continuous increase of TSS) on the degradation of coral reef in a long time scale or of different geographical scale. As it is important to monitor TSS changes timely and frequently, the TSS mapping method provides an approach to track TSS spatial-temporal variation 
for water quality assessment and policy making for the purpose of coral reef conservation. In the study, the Jiaowei (A) core area got more severe influence than Xilian (B) core area from tropical storm Soudelor.

Besides tropical storms and several other factors mentioned above, there may be other factors or events that cause the changes of water quality in a short or long term, such as seasonal and inter-annual variations in precipitation, river runoff and climate [52, 53, 54]. In future research, annual or seasonal TSS changes should be included in order to evaluate their variance in longer time span. In addition, considering the correlation between TSS and other water parameters (e.g. clarity, turbidity), as indicated by many previous studies in water areas $[55,1]$, more water quality parameters should be factored in in future studies to study/validate the spatial-temporal distribution and analysis of TSS concentration.

\section{Acknowledgements}

This research was partly funded by GDAS' Special Project of Science and Technology Development (2017GDASCX0101) and Water Conservancy Science \& Technology Innovation Project (2011-20) of Guangdong Province, China.

\section{References}

[1] Chen, S. S., Fang, L. G., Zhang, L. X., Huang, W. R. Remote sensing of turbidity in seawater intrusion reaches of Pearl River Estuary - A case study in Modaomen water way, China. Estuarine, Coastal and Shelf Science. Vol. 82, No. 1, 2009, pp. 119-127.

[2] Populus, J., Hastuti, W., Martin, J. L. M., Guelorget, O., Sumartono, B., Wibowo, A. Remote sensing as a tool for diagnosis of water quality in indonesian seas. Ocean \& Coastal Management. Vol. 27, No. 3, 1995, pp. 197-215.

[3] Washburn, L., McClure, K. A., Jones, B. H., Bay, S. M. Spatial scales and evolution of stormwater plumes in Santa Monica Bay. Marine Environmental Research. Vol. 56, Issues 1-2, 2003, pp. 103-125.

[4] Samuel, Dominggus., Awak, H. L. M. K., Jonson Lumban Gaol, Beginer Subhan, Hawis H. Madduppa, Dondy Arafat. Coral Reef Ecosystem Monitoring Using Remote Sensing Data: Case Study in Owi Island, Biak, Papua. Procedia Environmental Sciences, Vol. 33, 2016, pp. 600-606.

[5] Dekshenieks, M. M., Hofmann, E. E., Klinck, J. M., Powell, E. N. Quantifying the effects of environmental change on an oyster population: a modeling study. Estuaries. Vol. 23, No. 5, 2000, pp. 593-610.

[6] Avio, C. G., Gorbi, S., Regoli, F. Plastics and microplastics in the oceans: From emerging pollutants to emerged threat. Marine Environmental Research, Vol. 128, 2017, pp. 2-11.

[7] Fan, H., Huang, H. J. Response of coastal marine ecoenvironment to river fluxes into the sea: a case study of the Huanghe (Yellow) River mouth and adjacent waters. Marine Environmental Research. Vol. 65(5), 2008, pp. 378-387.
[8] Saiz-Salinas, J. I., Urkiaga-Alberdi, J. Faunal responses to turbidity in a man-modified bay (Bilbao, Spain). Marine Environmental Research. Vol. 47, No.4, 1999, pp. 331-347.

[9] Wang, H. Q., Hladik, C. M., Huang, W. R., Milla, K., Edmiston, L., Harwell, M. A., Schalles, J. F. Detecting the spatial and temporal variability of chlorophyll-a concentration and total suspended solids in Apalachicola Bay, Florida using MODIS imagery. International Journal of Remote Sensing. Vol. 31, No.2, 2010, pp. 1366-5901.

[10] Li-Ye Zhang, Shan-shan Chung, Jian-wen Qiu. Ecological carrying capacity assessment of diving site: A case study of Mabul Island, Malaysia. Journal of Environmental Management, Vol. 183, No 1, 2016, pp. 253-259.

[11] Hoegh-Guldberg, O. Climate change, coral bleaching and the future of the world's coral reefs. Marine and Freshwater Research. Vol. 50, No.8, 1999, pp. 839-866.

[12] Chen, J. Y., Mao, Z. H., and Zhang, H. G., et al. Analysis on coral reefs mapping using SPOT5 at Dongsha. Acta Oceanologia Sinica. Vol. 29, No.3, 2007, pp. 51-57.

[13] Acker, J. G., Vasilkov, A., Nadeau, D., \& Kuring, N. (). Use of SeaWiFS ocean color data to estimate neritic sediment mass transport from carbonate platforms for two hurricane-forced events. Coral Reefs. Vol 23, No.1, 2004, pp. 39-47.

[14] Carla I. Elliff, Ruy K. P. Kikuchi. Ecosystem services provided by coral reefs in a Southwestern Atlantic Archipelago. Ocean \& Coastal Management, Vol 136, 2017, pp. 49-55.

[15] Dahl, A L. Status and conservation of South Pacific coral reefs. Proc. 5th int. Coral Reef Congr. No.6, 1985, pp.509513.

[16] Pan, Yan-li, and Tang, Dan-ling, 2009. General introduction to satellite remote sensing of coral reef bleaching. ACTA ECOLOGICA SINICA, Vol. 29, No.9, pp.5077-5080.

[17] Erin K. Eastwood, Darien G. Clary, Don J. Melnick. Coral reef health and management on the verge of a tourism boom: A case study from Miches, Dominican Republic. Ocean \& Coastal Management, Vol. 138, No.15, 2017, pp. 192-204.

[18] Islam, M. M., M. M. Shamsuzzaman, M. M. H. Mozumder, X. M. Xu, M. Yu, Jewel, M. A. S.. Exploitation and conservation of coastal and marine fisheries in Bangladesh: Do the fishery laws matter? Marine Policy, Vol. 76, 2017, pp. 143-151.

[19] Goreau, T F. (1964). Mass expulsion of zoxanthellae from Jamaican Reef communities after hurricane Flora. Science, Vol. 145, pp.383-386.

[20] Yu, K. F. Zhao, J. X., Liu, T. S., Wei, G. H., Wang, P. X., Collerson, KD. (2004). T S High-frequency winter cooling and reef coral mortality during the Holocene climatic optimum. Each Planet Sci. Lett. Vol. 224, pp.143-155.

[21] Hollie M. Putnam, Katie L. Barott, Tracy D. Ainsworth, Ruth D. Gates. The Vulnerability and Resilience of Reef-Building Corals. Current Biology, Vol. 27, No. 11, 2017, pp. r528-r540.

[22] Liao, B. L., Li Liu, Chuwu Liu. Research status and prospect of Xuwen coral reef. Journal of Guangdong Ocean University. Vol.31, No.4, 2011, Pages 91-96.

[23] Niu, W. T., Xu, X. Z., Lin, R. C., Huang, D. Y. 2010. Effects of sedimentation on coral reefs and reef organisms. Marine Science Bulletin, Vol.29, NO.1, 2010. 
[24] Fabricius, M. Effects of terrestrial runoff on the ecology of corals and coral reefs: review and synthesis. Marine Pollution Bulletin. Vol. 50, 2005, pp.125-146.

[25] Hubbard, D K. Sedimentation as a control of reef development: St. Croix. Coral Reefs, Vol. 5, 1986, pp.117125 .

[26] Zhao, H., Wang, L. R., Song, C. J. 2006. The distribution and protection of the coral reefs in the west of Xuwen County. Tropical Geography, Vol.26, No. 3, pp.202-206.

[27] Rogers, C S. The marine environments of Brewers Bay, Perseverance Bay, Flat Cay and Saba Island, St Thomas, U. S. V. I., with emphasis on coral reefs and seagrass beds. Dept Conservation and Cultural Affairs, Gov't of the Virgin Islands, 1982, pp. 1-181.

[28] National Bureau of Oceanography of China. Bulletin of marine environment status of China in 2012. http://www.soa.gov.cn/, 2013.

[29] Chen, S. S, Huang, W. R., Chen, W. Q., Wang, H. Q. Remote sensing analysis of rainstorm effects on sediment concentrations in Apalachicola Bay, USA. Ecological Informatics, 2010, doi:10.1016/j.ecoinf.2010.12.001.

[30] Shuisen Chen, Liusheng Han, Xiuzhi Chen, Dan Li, Lin Sun, Yong Lia. Estimating wide range Total Suspended Solids concentrations from MODIS 250-m imageries: An improved method. ISPRS Journal of Photogrammetry and Remote Sensing, Vol. 99, 2015, pp. 58-69.

[31] Chiara Corbari, Fabio Lassini, Marco Mancini. Effect of intense short rainfall events on coastal water quality parameters from remote sensing data. Continental Shelf Research, Vol. 123, 2016, pp. 18-28.

[32] Hae-Cheol Kim, Seunghyun Son, Yong Hoon Kim, Jong Seong Khim, Jungho Nam, Won Keun Chang, Jung-Ho Lee, Chang-Hee Lee, Jongseong Ryu. Remote sensing and water quality indicators in the Korean West coast: Spatio-temporal structures of MODIS-derived chlorophyll-a and total suspended solids. Marine Pollution Bulletin, Vol. 121, Issues 1-2, 2017, pp. 425-434.

[33] Heyes, A., Miller, C., \& Mason, R. P. (2004). Mercury and methylmercury in Hudson River sediment: Impact of tidal resuspension on partitioning and methylation. Marine Chemistry, Vol. 90, No. 1-4, pp.75-89.

[34] Udy, J., Gall, M., Longstaff, B., Moore, K., Roelfsema, C., Spooner, D. R., Albert, S. (2005). Water quality monitoring: a combined approach to investigate gradients of change in the Great Barrier Reef, Australia. Marine Pollution Bulletin, Vol. 51, pp.224-238.

[35] Hellweger, F. L., Schlosser, P., Lall, U., Weissel, J. K., 2004. Use of satellite imagery for water quality studies in New York Harbor. Estuarine, Coastal and Shelf Science, Vol. 61, pp. $437-448$.

[36] Li, H., Mijail Arias, Anouk Blauw, Hans Los, Arthur E. Mynett, Steef Peters. Enhancing generic ecological model for short-term prediction of Southern North Sea algal dynamics with remote sensing images. Ecological Modelling, Vol. 221, Issue 20, 2010, pp. 2435-2446.

[37] Jiang, H. Retrieval of Total Suspended Sediment Concentration in Qingshan Lake by Hyperspectral Remote Sensing, JOURNAL OF ANHUI AGRICULTURAL
SCIENCES, Vol. 39, No. 15, 2011.

[38] Fu, X. M., Wang, C. Y., Shao, C. L., Han, L., LI, G. Q. 2009. Investigation on the Status of Coral Reef Resources and Medicinal Research in China 1I. Resource Decline Status, Protection and Management. Water quality-Determination of suspended substance-Gravimetric method, National standard of China. Periodical of Ocean University of China, Vol. 39, No. 4, 1990, pp.685-690. GB 11901-89.

[39] Forrester, A. 1997. The Effects of El Niño on Marine Life. Cambridge Scientific Abstracts Web site. http://www.csa.com/discoveryguides/archives/elnino.php.

[40] National Marine Fisheries Service (NMFS). 2001. NMFS Office of Protected Resources Web site. www.nmfs.noaa.gov/prot_res/PR/.

[41] Burt, J. A., S. Coles, H. van Lavieren, O. Taylor, K. SamimiNamin. Oman's coral reefs: A unique ecosystem challenged by natural and man-related stresses and in need of conservation. Marine Pollution Bulletin, Vol. 105, Issue 2, 2016, pp. 498506.

[42] Guangdong Provincial Oceanic and Fishery Bureau. The marine environment bulletin of Guangdong Province in 2016, http://www.gdofa.gov.cn/gzhd/zxft/201706/t20170614_84628 1.htm, 2016.

[43] Chen, S. S., Huang, W. R., Wang, H. Q., Li, D., 2009. Remote sensing assessment of sediment re-suspension during Hurricane Frances in Apalachicola Bay, USA. Remote Sensing of Environment, Vol. 113, No. 12, pp.2670-2681.

[44] Zhu, L., Wang, S, Zhou, Y. (2007). Estimation of suspended sediment concentration in Taihu Lake using MODIS image data. Advances in Water Science, Vol. 18, No. 3, pp. 444-450.

[45] Komick, N. M., Costa, M. P. F., \& Gower, J. (2009). Biooptical algorithm evaluation for MODIS for western Canada coastal waters: An exploratory approach using in situ reflectance. Remote Sensing of Environment, Vol.113, No. 4, pp.794-804.

[46] Martiny, N., Santer, R., \& Smolskaia, I. (2005). Vicarious calibration of MERIS over dark waters in the near infrared. Remote Sensing of Environment, Vol. 94, No. 4, pp.475-490.

[47] Verstraete, M. (1994). The contribution of remote sensing to monitor vegetation and to evaluate its dynamic aspects. In F. Veroustraete \& R. Ceulemans (Eds.), Vegetation, Modeling and Climatic Change Effects. The Hague, The Netherlands: SPB Academic Publishing. pp. 207-212.

[48] Chavez, P. S., 1988. An improved dark-object subtraction technique for atmospheric scattering correction of multispectral data. Remote Sensing of Environment, Vol. 24, pp.459-479.

[49] Shi, K., Li Y., Li, L.,. Lu, H., Song, K. S., Liu, Z. H., Xu, Y. F., Li, Z. C. (2013). Remote chlorophyll-a estimates for inland waters based on a cluster-based classification. Science of The Total Environment, Vol. 444, pp. 1-15.

[50] Majozi, Nobuhle P., et al, 2014. Remote sensing of euphotic depth in shallow tropical inland waters of Lake Naivasha using MERIS data. Remote Sensing of Environment, Vol. 148, 2014, pp. 178-189 
[51] Han, L. S. et al, 2014. Estimation of water clarity in offshore marine areas based on modified semi-analysis spectra model. Spectroscopy and Spectral Analysis, Vol. 34, Issue 2, pp477482.

[52] Janicki, A., Pribble, R., Janicki, S., \& Winowitch, M. (2001). An analysis of long-term trends in Tampa Bay water quality. Tampa Bay estuary technical report, Vol. 04-01, No. 48.

[53] Lipp, E. K., Schmidt, N., Luther, M., \& Rose, J. B. (2001).
Determining the effects of El Niño-southern oscillation events on coastal water quality. Estuaries, Vol. 24, pp. 491-497.

[54] Schmidt, N., \& Luther, M. (2002). ENSO impacts on salinity in Tampa Bay, Florida. Estuaries, Vol. 25, No. 5, pp. 976-984.

[55] Erftemeijer, Paul L. A., Riegl, Bernhard, Hoeksema, Bert W., Todd, Peter A. Environmental impacts of dredging and other sediment disturbances on corals: A review. Marine Pollution Bulletin, Vol. 64, Issue 9, 2012, pp. 1737-1765. 